\title{
TURBULENCE MODELING IN GEOPHYSICAL FLOWS - PART I - FIRST-ORDER TURBULENT CLOSURE MODELING
}

\author{
José Francisco Almeida de Souza', José Luiz Lima de Azevedo², Leopoldo Rota de Oliveira², \\ Ivan Dias Soares ${ }^{3}$ and Maurício Magalhães Mata²
}

\begin{abstract}
The usage of so-called turbulence closure models within hydrodynamic circulation models comes from the need to adequately describe vertical mixing processes. Even among the classical turbulence models; that is, those based on the Reynolds decomposition technique (Reynolds Averaged Navier-Stokes - RANS), there is a variety of approaches that can be followed for the modeling of turbulent flows (second moment) of momentum, heat, salinity, and other properties. Essentially, these approaches are divided into those which use the concept of turbulent viscosity/diffusivity in the modeling of the second moment, and those which do not use it. In this work we present and discuss the models that employ this concept, in which the viscosity can be considered constant or variable. In this latter scenario, besides those that use the concepts of mixture length, the models that use one or two differential transport equations for determining the viscosity are presented. The fact that two transport equations are used - one for the turbulent kinetic energy and the other for the turbulent length scale - make these latter ones the most complete turbulent closure models in this category.
\end{abstract}

Keywords: turbulence modeling, turbulence models, first-order models, first-order turbulent closure.

RESUMO. A descrição adequada dos processos de mistura vertical nos modelos de circulação hidrodinâmica é o objetivo dos chamados modelos de turbulência, os quais são acoplados aos primeiros. Mesmo entre os modelos clássicos de turbulência, isto é, aqueles que se baseiam na técnica de decomposição de Reynolds (Reynolds Averaged Navier-Stokes - RANS), existe uma variedade de abordagens que podem ser seguidas na modelagem dos fluxos turbulentos (segundos momentos) de momentum, calor, salinidade e outras propriedades. Fundamentalmente estas abordagens dividem-se entre aquelas que utilizam o conceito de viscosidade/difusividade turbulenta na modelagem dos segundos momentos, e aquelas que não 0 utilizam. Nesse trabalho são apresentados e discutidos os modelos que empregam este conceito, onde a viscosidade pode ser considerada constante ou variável. No caso variável, além daqueles que utilizam o conceito de comprimento de mistura, são ainda apresentados os modelos que utilizam uma ou duas equações diferenciais de transporte para a determinação da viscosidade. 0 fato de empregar duas equações de transporte, uma para a energia cinética turbulenta e outra para a escala de comprimento turbulento, fazem destes últimos os mais completos modelos de fechamento turbulento desta categoria.

Palavras-chave: modelagem da turbulência, modelos de turbulência, modelos de primeira ordem, fechamento turbulento de primeira ordem.

\footnotetext{
1 Escola de Engenharia - EE, Universidade Federal do Rio Grande - FURG, Campus Carreiros, Av. Itália, Km 8, Bairro Carreiros, 96201-900 Rio Grande, RS, Brazil. Phone: +55(53) 3233-6876 - E-mail: zefran.souza@gmail.com

2 Laboratório de Estudos dos Oceanos e Clima - LEOC, Instituto de Oceanografia - 10, Universidade Federal do Rio Grande - FURG, Campus Carreiros, Av. Itália, Km 8 , Bairro Carreiros, 96201-900 Rio Grande, RS, Brazil. Phone: +55(53)3233-6851/3233-6854/3233-6861 - E-mails: joseazevedo@furg.br; leopoldorota@yahoo.com.br; mauricio.mata@furg.br

${ }^{3}$ Associação ATLANTIS para o Desenvolvimento da Ciência - FURG, Rua Barão de Cotegipe, 653, 96200-290 Rio Grande, RS, Brazil. Phone: +55(53) 3233-5858 - E-mail: isoares@atlantis.org.br
} 


\section{INTRODUCTION}

The difficulty in acquiring data in situ - which combines factors such as the high costs involved, logistics, and access to the site, among other things - as well as the continued advancement of computational resources, has turned numerical modeling into an essential tool for the study of geophysical flows. Additionally, issues associated with global climate, offshore oil exploration, environmental management, and other things, increases the demand for data, which also reinforces the importance of numerical modeling for the development of studies addressing these themes. Ocean circulation, as a fundamental element in the questions raised above, will have its modeling addressed throughout this work.

The exchanges of heat and mass through the free surface, the action of surface and internal waves, the ebb and flow of the tide, and wind action on the surface, are competing forces which add complexity to the modeling of oceanic flows and the mixture processes involved. The difficulty of reproducing the individual or joint action of these forces on a laboratory scale explains the great interest that the numerical simulation of geophysical flows has aroused in researchers, especially from the 1980s onwards (MelIor \& Yamada, 1982; Hassid \& Galperin, 1983; Chao \& Boicourt, 1986; Chao, 1988; Galperin et al., 1989; Kantha \& Clayson, 1994; Nunes Vaz \& Simpson, 1994; Garvin, 1999; Verdier-Bonnet et al., 1999; Baumert \& Peters, 2000; Burchard \& Bolding, 2001; Liu et al., 2002; Warner et al., 2005; Ilicak et al., 2008; Marques et al., 2009; Canuto et al., 2010; Pimenta et al., 2011; and Palma \& Matano, 2012).

The correct description of vertical mixing processes in hydrodynamic circulation models is the function of the so-called turbulence models, which are linked to the former ones. It is interesting to observe that flows in the internal or external platform or in the ocean basin, and the circulation within an estuary or cove, under the action of strong or moderate winds, under diurnal surface warming or nocturnal cooling - in short, in each of these scenarios, it is interesting to observe that the relative importance of the turbulence production processes due to the shear or the buoyancy, as well as the destruction process induced by the combined action of the driving forces, is different, and the correct description of the mixing processes, in each case, will depend on the efficiency of the turbulence model (Burchard, 2002).

Various types of turbulent closure models have application in the numerical modeling of geophysical flows. Empirical models such as the K Profile Parameterization (KPP), models based on Reynolds decomposition (known for RANS models), and models based on Large Eddy Simulation (LES) models are found linked to various hydrodynamic models currently in use. Due to computational limitations, the technique of Direct Numerical Simulation (DNS), in which all the flow measures are solved, is not applicable to geophysical flows which invariably have a higher Reynolds number. A deeper discussion about KPP can be found in Large et al. (1994) and Durski et al. (2004); and, for LES and DNS, in Smagorinsky (1963), Silvestrini (2003), Lesieur et al. (2005), Martinez (2006), and Pope (2008).

This article aims to present and discuss turbulence models based on the Reynolds decomposition technique, better known as Reynolds Averaged Navier-Stokes (RANS). Models of this type are mostly used in numerical models for geophysical flow simuIation (e.g., HYCOM, POM, ROMS, TELEMAC, and others), due to their simplicity when compared to other types of models (LES and DNS), as well as their low computational cost (e.g., Silvestrini, 2003).

These models may be subdivided into two groups (Yamada \& Mellor, 1974; Rodi, 1993; Burchard, 2002; Pope, 2008), as follows: (i) they use the concept of turbulent viscosity/diffusivity; or (ii) they do not use this concept. This paper presents models from the first group, which can be subdivided into turbulence models with constant turbulent viscosity and variable viscosity (zero-equation models), and other more complex models that employ one or two differential transport equations (models with one and two equations) to determine the viscosity.

Numerous studies found in the literature cite the use of these turbulence models in many geophysical applications. Xing \& Davies (1999), for example, used these models for turbulence modeling in order to study the influence of the intensity and direction of the wind on the spreading of the plume of wavy water formed by the discharge of a river into the coastal region. Liu et al. (2002) also applied these models to simulate the transient stratification of the estuarine system of the Thanshui river in Taiwan. Warner et al. (2005) compared the performance of four turbulent closure RANS type models coupled to a three-dimensional oceanic circulation model. For this, they conducted some tests, including one involving estuarine circulation in a long rectangular channel, forced by river discharge at the head and the tidal current at the mouth (saline water). Blaise et al. (2007), in turn, used RANS models in the investigation of the tidal flow around Rattray Island, in the Great Barrier Reef, in Australia, which gives rise to vortices in the wake of the motion.

This article is organized as follows: first we present the basic equations of motion and the Reynolds decomposition technique. Then, we present the equations of the average flow and the additional unknowns introduced by the averaging process, and also discuss the problem of turbulent closure. Subsequently, the 
turbulence models with zero, one and two equations are presented. Also, the main concepts for parameterization of the unknown correlations are presented, and finally, the discussion and concluding remarks.

\section{GOVERNING EQUATIONS}

The starting point for the study of turbulence is the equations of continuity, momentum, and scalar transport, applied to a fluid assumed to be incompressible. The equations are described below. ${ }^{1}$

Equation of Continuity

$$
\frac{\partial \tilde{u}_{i}}{\partial x_{i}}=0
$$

Equation of Momentum

$$
\begin{gathered}
\frac{\partial \tilde{u}_{i}}{\partial t}+\tilde{u}_{j} \frac{\partial \tilde{u}_{i}}{\partial x_{j}}-f \tilde{u}_{j} \varepsilon_{i j 3} \\
=-\frac{1}{\rho_{o}} \frac{\partial \tilde{p}}{\partial x_{i}}-\frac{\tilde{\rho} g}{\rho_{o}} \delta_{13}+\nu \frac{\partial^{2} \tilde{u}_{i}}{\partial x_{j}^{2}}
\end{gathered}
$$

Transport Equation

$$
\frac{\partial \tilde{\varphi}}{\partial t}+\tilde{u}_{j} \frac{\partial \tilde{\varphi}}{\partial x_{j}}=\Gamma \frac{\partial^{2} \tilde{\varphi}}{\partial x_{i}^{2}}
$$

In these equations, $\tilde{u}, \tilde{v}, \tilde{w}, \tilde{p}$ and $\tilde{\varphi}$ represent the instantaneous values of the components of the velocity, pressure, and scalar property which could be representing the temperature or salinity, while $\nu$ and $\Gamma$ are the coefficients of viscosity and molecular diffusion, respectively. The Boussinesq approximation was implicitly adopted in Equation (2). Equation (1) expresses the conservation of mass for an incompressible fluid. Starting from the left, the terms of Equation (2) correspond to: i) local variation, (ii) advective variation, (iii) Coriolis acceleration (due to the rotation of the Earth), (iv) the pressure gradient term, (v) the buoyancy term, and (vi) the friction term. The terms on the left hand side of Equation (3) describe the local variation term and advective term of the scalar $\phi$, respectively, while the term on the right hand side corresponds to the diffusion of this scalar.

The equations above are exact and provide the solution at each point and instant, and, therefore, do not need to (explicitly) include any turbulence term. This is already solved, or is already implicitly included in the instantaneous values that appear in the equations. This set of equations correctly represents any type of flow, as long as the appropriate boundary and initial conditions are provided. However, the lack of an analytical solution to these equations obliges us to resort to numerical resources in order to achieve such a solution. Although we have numerical procedures for solving Equations (1) to (3), the processing speed and the storage capacity of computers is still not good enough to allow the resolution of any turbulent geophysical flow of practical interest.

The need to solve practical problems led to the adoption of an approach introduced by Reynolds, known as the "decomposition technique" which is widely used in modeling. This technique consists of separating the instantaneous flow into an average part or component, (on a large scale) and another floating component (on a small scale), from which only the global effect on the average flow will be considered. This procedure will be exemplified by using the same velocity database as Müller et al. (1998) and Oliveira (2003), which was obtained by a current measurer anchored at latitude $27.54^{\circ} \mathrm{S}$ on the axis of the Brazil Current at a depth of $220 \mathrm{~m}$. Figure 1a shows a segment of the instantaneous (gross) temporal series of meridional velocity obtained by this instrument, which contains a total of 960 pieces of data, stored at intervals of $2 \mathrm{~h}$ and with a total sampling period of 80 days. Figure $1 \mathrm{~b}$ shows the same series after $40 \mathrm{~h}$ of low pass filtering; that is, it shows the average value of the current's meridional velocity for this time scale. Finally, Figure 1c shows the fluctuations of this velocity, which were obtained by subtracting the average value (Fig. 1b) from the instantaneous series (Fig. 1a).

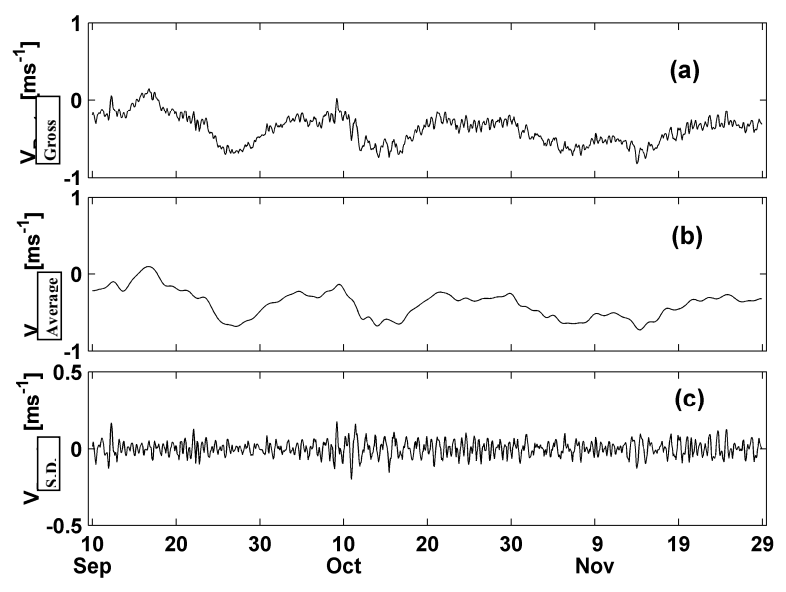

Figure 1 - Fluctuations in the flow.

The application of this decomposition technique is done in two steps: (i) the instantaneous variables that appear in the equations of motion (1) to (3) are decomposed into an average part and a floating part; and (ii) the average temporal operator is used in the equations resulting from the previous step, thereby obtaining the average component of the flow.

\footnotetext{
${ }^{1}$ The equations are presented in indicial notation. The reader who is unfamiliar with this notation can refer to sections 1.2 and 1.3 of Schwind (1980).
} 


\section{EQUATIONS OF AVERAGE FLOW}

After the decomposition of the flow into an average part (large scale) and another floating part (small scale), followed by application of the average temporal operator to the resulting equations, we obtain the equations of average flow, which are presented below. Further details regarding this procedure can be found in Stull (1988) and Kundu \& Cohen (2002).

Equation of Continuity:

$$
\frac{\partial U_{i}}{\partial x_{i}}=0
$$

Equation of Momentum

$$
\begin{gathered}
\frac{\partial U_{i}}{\partial t}+U_{j} \frac{\partial U_{i}}{\partial x_{j}}-f U_{j} \varepsilon_{i j 3} \\
=-\frac{1}{\rho_{o}} \frac{\partial P}{\partial x_{i}}-\frac{\rho \mathrm{g}}{\rho_{o}} \delta_{i 3}+\frac{\partial}{\partial x_{j}}\left(\nu \frac{\partial U_{i}}{\partial x_{j}}-\overline{u_{i} u_{j}}\right)
\end{gathered}
$$

Heat Transport Equation

$$
\frac{\partial \Theta}{\partial t}+U_{i} \frac{\partial \Theta}{\partial x_{i}}=\frac{\partial}{\partial x_{i}}\left(\Gamma \frac{\partial \Theta}{\partial x_{i}}-\overline{u_{i} \theta}\right)
$$

Salt Transport Equation

$$
\frac{\partial S}{\partial t}+U_{i} \frac{\partial S}{\partial x_{i}}=\frac{\partial}{\partial x_{i}}\left(\Gamma \frac{\partial S}{\partial x_{i}}-\overline{u_{i} s}\right)
$$

The variables written with a capital letter represent average values, while those in lowercase letters represent the fluctuations around these values. In the equations, $\nu=1.0 \cdot 10^{-6} \mathrm{~m}^{2} \mathrm{~s}^{-1}$ represents the molecular viscosity of the water, while the molecular diffusivities are given the values $\Gamma_{\theta}=1,38 \cdot 10^{-7} \mathrm{~m}^{2} \mathrm{~s}^{-1}$ for the heat and $\Gamma_{s}=1,1 \cdot 10^{-9} \mathrm{~m}^{2} \mathrm{~s}^{-1}$ for the salt (Burchard, 2002).

It is observed that in the momentum equation (5), after averaging the smaller turbulent fluctuations, the term $\overline{u_{i} u_{j}}$ remained. This represents the global effect of the turbulence process on the average flow, which, when multiplied by the specific mass, acquires the dimensions of stress. The resulting term can be interpreted as a turbulent flow of momentum; however, using the statistical approach for turbulence, it is seen as a correlation of the velocity fluctuations, a second-order moment, or even as a second moment.

Although the term $\overline{u_{i} u_{j}}$ has its origin in the non-linearities of the inertia terms of Equation (2), it is usually grouped with viscous stress, as shown by the last term on the right hand side of
Equation (5). This is reasonable because the effect of these fluctuations on the average flow is to increase the diffusion of momentum, a similar role to that played by viscous stress. It should be noted that $\overline{u_{i} u_{j}}$ represents nine components of the so-called Reynolds tensor $\tau_{i j}$, given by:

$$
\tau_{i j}=\rho \overline{u_{i} u_{j}}=\rho\left(\begin{array}{lll}
\overline{u_{1} u_{1}} & \overline{u_{1} u_{2}} & \overline{u_{1} u_{3}} \\
\overline{u_{2} u_{1}} & \overline{u_{2} u_{2}} & \overline{u_{2} u_{3}} \\
\overline{u_{3} u_{1}} & \overline{u_{3} u_{2}} & \overline{u_{3} u_{3}}
\end{array}\right)
$$

It is worth noting that $\tau_{i j}$ is symmetrical, since:

$$
\overline{u_{1} u_{2}}=\overline{u_{2} u_{1}} \quad \overline{u_{1} u_{3}}=\overline{u_{3} u_{1}} \quad \overline{u_{2} u_{3}}=\overline{u_{3} u_{2}}
$$

We see then that the Reynolds tensor has only six independent components. The score of the tensor (i.e., the sum of the elements of the main diagonal) represents, by definition, twice the turbulent kinetic energy $k$ defined by

$$
k=\frac{\overline{u_{1}^{2}}+\overline{u_{2}^{2}}+\overline{u_{3}^{2}}}{2}
$$

Equations (1) and (2) solve the flow hydrodynamics that one desires to model (velocity and pressure field), while (3) solves the scalar transport (distribution of $\varphi$ ). It is notable that, without considering the scalar transport, we need to determine the three components of the velocity $\tilde{u}_{i}$ and the pressure $\tilde{p}$ in the hydrodynamic system formed by Equations (1) and (2). Therefore, this system is closed in the sense that the number of unknowns is equal to the number of equations (four). Meanwhile, in the system of Equations (4) and (5) of the average flow, there are four equations (averages) and ten unknowns to determine (six more), because the decomposition technique introduced six new unknowns: the correlations between the fluctuations of velocity $\overline{u_{i} u_{j}}$. The system is now said to be "open" and the solution will only be possible if these correlations are determined, or estimated, in some way that is independent of the system formed by Equations (4) and (5). The independent determination of these correlations, so that the number of unknowns (ten) adjusts to the number of available equations (four), is called "closure" or a "closure problem" of the turbulence.

The determination of the correlations $\overline{u_{i} u_{j}}, \overline{u_{i} \theta}$ and $\overline{u_{i} s}$ is the main goal of the "turbulence modeling". There are several techniques for the modeling of these terms, including: (i) Reynolds decomposition (RANS), whose models may or may not use the concept of turbulent viscosity/diffusivity; (ii) direct numerical simulation, in which the models solve the 3D equations for the instantaneous variables (DNS), covering all the turbulence scales; and (iii) simulation of the large scales of the turbulent flow (LES), a technique which uses a spatial filter for separating the 
large scales from the small ones, thereby parameterizing the latter (e.g., Silvestrini, 2003; Martinez, 2006).

The first of these techniques is widely used in the modeling of geophysical flows, while the others, although reasonably well developed, have applications limited to areas that are relatively small in flows with a low Reynolds number. It is worth noting that, in this study, the RANS models that use the concept of turbulent viscosity/diffusivity will be addressed. Those not using this concept, because of their greater complexity, will be the subject of Part II of this work (Souza et al., manuscript submitted for publication).

\section{MODELS BASED ON THE CONCEPT OF TURBULENT VISCOSITY}

The assumption that the Reynolds stresses, which appeared in Equation (5), are proportional to the deformation of the average flow, in an analogy with the viscous stresses, led Boussinesq to propose the concept of a turbulent viscosity, corresponding to molecular viscosity. He imagined the vortices to be portions of fluid that collide and exchange quantities of movement among themselves, just like the molecules in kinetic theory. According to this theory, the molecular viscosity is proportional to a characteristic velocity of the molecules and the average free path between the collisions. To complete the analogy, Boussinesq devised a hypothetical viscosity, called apparent or turbulent viscosity, which should be proportional to a typical velocity of the fluctuations of the turbulent motion and to a typical length of this motion (e.g., Rodi, 1993). A more detailed discussion of this analogy can be found in Souza et al. (2011). Despite the imperfections of the analogy, most of the turbulence models in use are based on this concept. As a result, turbulence models which are based on this concept will be addressed without, and also with one and with two differential transport equations.

\section{Zero-equation models}

Models of this type are very simple and use the concept of turbulent viscosity proposed by Boussinesq in 1877, which was the first attempt at modeling turbulence. These models are based on the analogy between the viscous stresses (molecular) and the Reynolds stresses, and they are expressed by the equations

$$
-\overline{u_{i} u_{j}}=K_{M}\left(\frac{\partial U_{i}}{\partial x_{j}}+\frac{\partial U_{j}}{\partial x_{i}}\right)-\frac{2}{3} k \delta_{i j}
$$

and, for the transport of scalars:

$$
-\overline{u_{i} \varphi}=K_{\varphi} \frac{\partial \Phi}{\partial x_{i}}
$$

Use of the turbulent viscosity concept in the turbulence models, besides introducing some conceptual shortcomings, such as the fact that this is not a property of the fluid, transfers the problem of indetermination of the Reynolds stresses to the problem of indetermination of the turbulent viscosity coefficient.

\section{a) Constant viscosity}

Some models use a constant turbulent viscosity coefficient throughout the area of the flow. In fact, adopting a constant value for this coefficient and introducing it into Equation (9) does not quite constitute a turbulence model itself - although this procedure is widely used, mainly to resolve hydraulic problems (e.g., Rodi, 1993). In many models, also in accordance with this author, the turbulence terms in the momentum equations are neglected. It is worth noting that many times a viscosity coefficient is introduced just to provide numerical stability.

It should be noted that the adoption of constant turbulent viscosity/diffusivity means considering it to be isotropic and homogeneous. Sometimes we relax this concept of isotropy and we consider coefficients that are constant but different in the horizontal and vertical directions. When the turbulent terms significantly influence the behavior of the flow, then the adoption of a constant coefficient denotes a conception that is too crude (e.g., Eiger, 1989; Rodi, 1993). The relationship between the turbulent viscosity and diffusivity coefficients obeys Equation (11),

$$
K_{H}=\frac{K_{M}}{\sigma}
$$

in which $\sigma=\operatorname{Pr}$ is dimensionless and known as a turbulent Prandtl number for the transport of heat, and $\phi=S c$ is called the turbulent Schmidt number for the transport of other scalars (salt, kinetic energy, dissipation rate, and others).

The concept of constant viscosity/diffusivity is most important in the two-dimensional models (called 2DH models), in which the equations are averaged in the water column and only the horizontal transport is considered. In these models, the vertical transport of momentum is represented by the friction stresses on the surface $\left(\tau_{s}\right)$ and at the bottom $\left(\tau_{b}\right)$ [e.g., Rodi, 1993].

\section{b) Variable viscosity - mixing length models}

The first model to consider the possible variation of turbulent viscosity, and therefore, the first turbulence model itself, was proposed by Prandtl in 1925 and became known as the Prandtl mixing length model (e.g., Rodi, 1993). In the kinetic theory of gases, the viscosity is proportional to a velocity scale $\hat{V}$ and a length scale $L$, with both characterizing large scale turbulent 
motion, as shown by the expression

$$
K_{M} \propto \hat{V} \cdot L
$$

Based on this, Prandtl postulated that, in (12), $\hat{V}$ is equal to the product of the average velocity gradient and the mixing length $\ell_{m}$, and $L$, the length scale, is the mixing length $\ell_{m}$ itself (see Souza et al., 2011). Thus, considering that the average flow occurs in the $x-y$ horizontal plane and that the horizontal velocities, $U$ and $V$, vary in the vertical direction $z$, the turbulent viscosity coefficient described by (12) will (for three-dimensional flow) be given by:

$$
K_{M}=\ell_{m}^{2} \sqrt{\left(\frac{\partial U}{\partial z}\right)^{2}+\left(\frac{\partial V}{\partial x}\right)^{2}}
$$

It is worth noting that the problem of the indetermination of $K_{M}$ is now transferred to another turbulent entity, $\ell_{m}$, which needs to be specified. The mixing length should in some way represent the size of the vortices of the flow which are responsible for the transport of the turbulent kinetic energy. A limitation of this model is the fact that it only produces acceptable results for flows having a characteristic dimension (e.g., Eiger, 1989), as is the case of the flows in large channels or geophysical flows whose horizontal scale is much larger than the vertical one. In these cases, the depth represents this characteristic length.

When we approach a wall or bottom (see Fig. 2), the scale of the mixing length, or the vortices of interest, decreases in such a manner that it is well accepted that $\ell_{m}=\kappa \cdot z$, with " $z$ " being the perpendicular distance to the wall and " $\kappa$ ", the von Karman constant, equal to 0.4. This expression shows that, when we move away from the wall, the characteristic size of the vortices grows and is inclined to do so up to the characteristic size of the flow or a threshold value, when the wall then fails to exert any influence on the local turbulence. A ramp model up to $25 \%$ of the depth, as shown in Figure 2, has been used with good results (e.g., Eiger, 1989). From this depth, this model considers the mixing length to be constant and equal to $0.25 \mathrm{H}$.

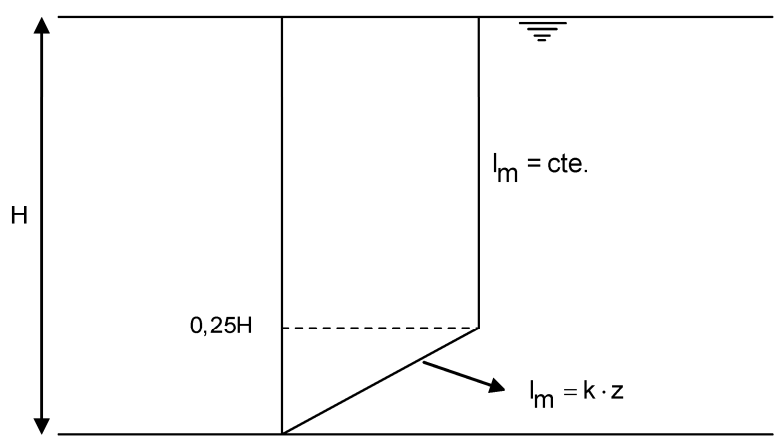

Figure 2 - Distribution of the length scale near a surface.

\section{Influence of stratification}

Stratification can affect the mixing processes considerably, acting as a kind of "shock absorber" for the turbulent fluctuations (i.e., it inhibits the turbulence) and thus affect the viscosity/diffusivity coefficients. In the turbulence models this influence is normally considered through the Richardson gradient number, $R i$, which is defined as (Kundu \& Cohen, 2002):

$$
R i=-\frac{\mathrm{g}}{\rho} \frac{\partial \rho / \partial z}{(\partial U / \partial z)^{2}}
$$

Equation (14), where the " $z$ " axis is vertical and oriented from the bottom upwards, can be interpreted as a balance between stabilizing forces of the stratification, which tend to hinder the processes of turbulent mixing (numerator), and the generating forces of turbulence (denominator), represented by the vertical shear of the flow velocity (Souza, 2011). This means that, if the density increases with the depth, it will be necessary to produce more turbulence to generate the same mixing intensity, since the medium will be more stratified and stable in this condition (e.g., Eiger, 1989).

If $\rho_{S}$ represents the density near the surface, $\rho_{F}$ the density near the bottom, and the numerator of (14) is written in finite form, then we have:

$$
\frac{\Delta \rho}{\Delta z}=\frac{\rho_{S}-\rho_{F}}{\Delta z}
$$

If the denominator of Equation (14) is kept constant, then the Richardson gradient number may be interpreted as:

$$
\begin{aligned}
& \rho_{S}<\rho_{F} \Rightarrow R i>0 \Rightarrow \text { Stable } \quad \therefore K_{M} \text { is smaller } \\
& \text { stratification } \\
& \rho_{S}<\rho_{F} \Rightarrow R i=0 \Rightarrow \text { Neutral } \quad \therefore K_{M} \\
& \text { stratification } \\
& \rho_{S}<\rho_{F} \Rightarrow R i<0 \Rightarrow \begin{array}{l}
\text { Unstable } \\
\text { stratification }
\end{array} \quad \therefore K_{M} \text { is greater }
\end{aligned}
$$

Depending on the type and intensity of the stratification, the viscosity/diffusivity coefficients need to be corrected. There exist some proposals for this correction, including that of Munk \& Anderson (1948), apud Nunes Vaz \& Simpson (1994):

$$
\begin{aligned}
K_{M} & =K_{M o}\left(1+10 R_{i}\right)^{-1 / 2} \\
K_{H} & =K_{H o}\left(1+3.33 R_{i}\right)^{-3 / 2}
\end{aligned}
$$

In the expressions of (16), $K_{M o}\left(K_{H o}\right)$ is the viscosity (diffusivity) in neutral stratification conditions $(R i=0)$, determined in accordance with Figure 2. 


\begin{tabular}{|l|c|}
\hline \multicolumn{1}{|c|}{ Equations } & Unknowns \\
\hline$\frac{\partial U_{i}}{\partial x_{i}}=0$ & $U, V, W, P$ \\
$\frac{\partial U_{i}}{\partial t}+U_{j} \frac{\partial U_{i}}{\partial x_{j}}-f U_{j} \varepsilon_{i j 3}=-\frac{1}{\rho_{o}} \frac{\partial P}{\partial x_{i}}-\frac{\rho \mathrm{g}}{\rho_{o}} \delta_{i 3}+\frac{\partial}{\partial x_{j}}\left(\nu \frac{\partial U_{i}}{\partial x_{j}}-\overline{u_{i} u_{j}}\right)$ & $-\overline{u_{i} u_{j}}$ \\
\hline$\frac{\partial \Theta}{\partial t}+U_{i} \frac{\partial \Theta}{\partial x_{i}}=\frac{\partial}{\partial x_{i}}\left(\Gamma_{\theta} \frac{\partial \Theta}{\partial x_{i}}-\overline{u_{i} \theta}\right)$ & $\Theta,-\overline{u_{i} \theta}$ \\
\hline$\frac{\partial S}{\partial t}+U_{i} \frac{\partial S}{\partial x_{i}}=\frac{\partial}{\partial x_{i}}\left(\Gamma_{s} \frac{\partial S}{\partial x_{i}}-\overline{u_{i} s}\right)$ & $S,-\overline{u_{i} s}$ \\
\hline$-\overline{u_{i} u_{j}}=K_{M}\left(\frac{\partial U_{i}}{\partial x_{j}}+\frac{\partial U_{j}}{\partial x_{i}}\right)$ & $K_{M}$ \\
\hline$-\overline{u_{i} \theta}=K_{H} \frac{\partial \Theta}{\partial x_{i}}$ and $-\overline{u_{i} s}=K_{H} \frac{\partial S}{\partial x_{i}}$ & $K_{H}$ \\
\hline $\begin{array}{l}K_{M}=K_{M o}\left(1+10 R_{i}\right)^{-1 / 2} \\
K_{H}=K_{H o}\left(1+3.33 R_{i}\right)^{-3 / 2}\end{array}$ & \\
\hline$K_{M o}=C t e$ & $K_{H o}=K_{M o} / \sigma$ \\
\hline$\ell_{m}\left(\right.$ ramp model from Fig. 2) and $K_{M o}=\ell_{m}^{2} \sqrt{\left(\frac{\partial U}{\partial z}\right)^{2}+\left(\frac{\partial V}{\partial z}\right)^{2}}$ & \\
\hline
\end{tabular}

$\left(^{\star}\right)$ Constant viscosity

$\left.{ }^{* *}\right)$ Variable viscosity

Summary of the equations: The table above presents a summary of the equations which describe the average flow and the turbulence model (with the variants: constant viscosity and variable viscosity).

To circumvent the limitation of the zero-equation models, which do not consider the influence of the turbulence at one point over others, models were developed that take into account the transport of characteristic quantities of the turbulence. In these models, it is necessary to solve one or two differential transport equations according to whether one or two of these characteristic quantities is considered. Such models receive the designation of one-equation models and two-equation models, respectively. The following topic presents the model that uses only one transport equation, in which the transported entity is the turbulent kinetic energy.

\section{Models with one equation}

In an analogy with the kinetic theory of gases, the turbulent viscosity should be proportional to a velocity scale and a length scale [see expression (12)]. Thus, the quantity of greatest physical sig- nificance for the representation of this velocity scale is the turbulence intensity, defined by $\sqrt{k}$, in which $k$ is the kinetic energy of the turbulent motion (per unit of mass). In accordance with Equation (8), one can see that $k$ is a direct measurement of the intensity of the turbulent fluctuations in the three directions of the motion (e.g., Rodi, 1993). With this consideration and the introduction of an empirical constant $c$, expression (12) takes the following form:

$$
K_{M}=c \sqrt{k} \cdot L
$$

in which $c$ is a proportionality coefficient that provides information about the state of stratification in the water column (stable, unstable, or neutral stratification). This coefficient is called the damping function or stability function (e.g., Vaz Nunes \& Simpson, 1994).

Expression (17) is known as the "Prandtl-Kolmogorov model" because both authors introduced the model independently (e.g., Rodi, 1993). Of course, the quantities present in (17) must be specified in some way. In this model, the distribution of the turbulent kinetic energy is determined by solving a differential transport equation for $k$, which can be obtained accurately from the 
Navier-Stokes equations which, after some algebraic manipulation, results in the transport equation for the turbulent kinetic energy. The development of this expression, which is presented below, and the interpretation of its terms, can be found in Chapter 13 of Kundu \& Cohen (2002). In this, $\rho_{o}$ is the constant reference density, while $\rho^{\prime}$ represents the fluctuations in the density field.

$$
\begin{gathered}
\frac{\partial k}{\partial t}+U_{j} \frac{\partial k}{\partial x_{j}}=-\underbrace{\overline{u_{i} u_{j}} \frac{\partial U_{i}}{\partial x_{j}}}_{P_{k}}-\underbrace{\frac{g}{\rho_{o}}\left(\overline{u_{i} \rho^{\prime}} \delta_{i 3}\right)}_{P_{B}} \\
-\underbrace{\frac{\partial}{\partial x_{j}}\left\{\overline{u_{j}\left(\frac{u_{i} u_{i}}{2}+\frac{p}{\rho_{o}}\right)}-\Gamma \frac{\partial k}{\partial x_{j}}\right\}}_{D}-\underbrace{\nu \overline{\frac{\partial u_{i}}{\partial x_{j}} \frac{\partial u_{i}}{\partial x_{j}}}}_{\varepsilon}
\end{gathered}
$$

Equation (18) - in which $k$ is expressed in $\mathrm{J} / \mathrm{kg}$ and each term has the unit W/ $\mathrm{kg}$ - has on its left hand side the variation rate of the turbulent kinetic energy. On its right hand side, we have four terms: (i) the first, $P_{k}$, can be interpreted as the production of turbulent kinetic energy due to the shear of the average flow; (ii) the term $P_{B}$ corresponds to the production of turbulent kinetic energy by buoyancy forces; (iii) $D$ may be associated with the transport of turbulent kinetic energy performed by the forces of viscous and turbulent origin; and (iv) the term $\varepsilon$ represents the dissipation of the turbulent kinetic energy. This equation is not used in turbulence models in the exact form, as presented in (18), because the correlations contained in the terms on its right hand side are unknown and need to be parameterized (e.g., Rodi, 1993; Burchard, 2002), which will be presented below.

a) Modeling of the term $P_{k}$ - using the concept of turbulent viscosity and Equation (9), one can write

$$
\begin{gathered}
P_{k}=-\overline{u_{i} u_{j}} \frac{\partial U_{i}}{\partial x_{j}} \\
=K_{M}\left(\frac{\partial U_{i}}{\partial x_{j}}+\frac{\partial U_{j}}{\partial x_{i}}\right) \frac{\partial U_{i}}{\partial x_{j}}-\frac{2}{3} k \delta_{i j} \frac{\partial U_{i}}{\partial x_{j}}
\end{gathered}
$$

Note that the last term is cancelled because $\delta_{i j}=0$ for $i \neq j$ and, when $i=j$ it is the derivative which is cancelled due to the continuity equation. Thus, the final form of this term is given by

$$
P_{k}=K_{M}\left(\frac{\partial U_{i}}{\partial x_{j}}+\frac{\partial U_{j}}{\partial x_{i}}\right) \frac{\partial U_{i}}{\partial x_{j}}
$$

b) Modeling of the term $P_{B}$ - this term only exists for $i=3$ and can be written as:

$P_{B}=-\frac{g}{\rho_{o}}\left(\overline{u_{i} \rho^{\prime}} \delta_{i 3}\right)=-\frac{g}{\rho_{o}}\left(\overline{w \rho^{\prime}}\right)=\frac{g}{\rho_{o}}\left[K_{H} \frac{\partial \rho}{\partial x}\right]$
The square of the Brunt-Väissälä frequency, $N^{2}$, is defined by $N^{2}=-\left(\mathrm{g} / \rho_{o}\right) \partial \rho / \partial z$; thus, (20) can be written as:

$$
P_{B}=K_{H} \frac{\mathrm{g}}{\rho_{o}} \frac{\partial \rho}{\partial z}=-K_{H} \cdot N^{2}
$$

in which $K_{H}$ is the diffusivity of the buoyancy.

c) Modeling of the term $D$ - the first part of the term between braces, of a turbulent nature, contains poorly understood correlations (e.g., Eiger, 1989), but its diffusive character suggests that it is modeled in accordance with the flow-gradient relationship expressed by Equation (10). The difficulties associated with this modeling are due to the correlation between the fluctuations of the velocity and pressure fields, something which is very difficult to assess experimentally (e.g., Fontoura Rodrigues, 2003). Thus, expressing this part as a function of the gradient $k$, we have

$$
\overline{-u_{j}\left(\frac{u_{i} u_{i}}{2}+\frac{p}{\rho_{o}}\right)}=K_{k} \frac{\partial k}{\partial x_{j}}
$$

in which $K_{k}=K_{M} / \sigma_{k}$ is the diffusion coefficient of the turbulent kinetic energy and $\sigma_{k}$ is the turbulent Schmidt number, which is usually assumed to be unitary. The second part of the term $D$ represents the molecular diffusion of the turbulent kinetic energy (TKE). Thus, we can write this term as follows:

$$
\begin{aligned}
D & =\frac{\partial}{\partial x_{j}}\left\{-\overline{u_{j}\left(\frac{u_{i} u_{i}}{2}+\frac{p}{\rho_{o}}\right)}+\Gamma \frac{\partial k}{\partial x_{j}}\right\} \\
& =\frac{\partial}{\partial x_{j}}\left[\left(\frac{K_{M}}{\sigma_{k}}+\Gamma\right) \frac{\partial k}{\partial x_{j}}\right]
\end{aligned}
$$

Also according to Eiger (1989), the term $D$ probably forms at the weakest point of the modeled form of Equation (18). It is worth noting that when the molecular diffusivity is neglected in expression (23), in its place a minimum value (background) should be provided for the turbulent diffusion coefficient. Also worthy of attention is that the term $D$ does not contribute to the global level of turbulent kinetic energy - it only acts in its redistribution in the three directions and for this reason is known as the return-toisotropy term.

d) Modeling of the term $\varepsilon$ - this term is the dissipation rate of the turbulent kinetic energy in heat, which mainly occurs in the small scales of the turbulence. However, most of the energy of the turbulence is contained in the large vortices that feed the small vortices (see Souza et al., 2011). Thus, the availability of energy in the small scales depends on the transfer process which, in turn, depends on the large scales of the turbulence, which are associated with the kinetic energy $k$ and with the length scale $L$ - characteristics of the largest vortices. Dimensional considerations and 
experimental observations lead to the following estimate for the term $\varepsilon$ :

$$
\varepsilon=\nu \overline{\frac{\partial u_{i}}{\partial x_{j}} \frac{\partial u_{i}}{\partial x_{j}}}=c_{L} \frac{k^{3 / 2}}{L}
$$

in which $c_{L}=0.17$ is an empirical constant. The unit of $\varepsilon$ is [ $\mathrm{kg}^{-1} \mathrm{~S}^{-1}$ ]. Finally, substituting expressions (19), (20), (23), and (24) in Equation (18), we obtain the modeled form of this equation, given by

$$
\begin{gathered}
\frac{\partial k}{\partial t}+U_{j} \frac{\partial k}{\partial x_{j}}=\underbrace{K_{M}\left(\frac{\partial U_{i}}{\partial x_{j}}+\frac{\partial U_{j}}{\partial x_{i}}\right) \frac{\partial U_{i}}{\partial x_{j}}}_{P_{k}} \\
+\underbrace{K_{H} \frac{g}{\rho_{o}} \frac{\partial \rho}{\partial z}}_{P_{B}}+\underbrace{\frac{\partial}{\partial x_{j}}\left[\left(\frac{K_{M}}{\sigma_{k}}+\Gamma\right) \frac{\partial k}{\partial x_{j}}\right]}_{D}-\underbrace{c_{L} \frac{k^{3 / 2}}{L}}_{\varepsilon}
\end{gathered}
$$

With Equations (17) and (25), the indetermination now passes to the turbulence's characteristic length scale $L$. Various ways for prescribing this length scale can be found in the literature, among them, $L=\kappa z$, as shown above. Mellor \& Yamada (1974 and 1982) suggest that the length scale $L$ could be prescribed by the following expression:

$$
L=\ell_{o} \frac{\kappa z}{\kappa z+\ell_{o}}
$$

in which,

$$
\ell_{o}=\alpha \frac{\int_{0}^{\infty} \sqrt{k}|z| d z}{\int_{0}^{\infty} \sqrt{k} d z}
$$

In these expressions, $\kappa$ is the von Karman constant, $\alpha=0.1$ is a constant, $z$ is the distance from the point considered to the wall of the boundary, $\sqrt{k}$ is the turbulent velocity scale, and $\ell_{o}$ is a length scale related to the intensity of the turbulence at the point considered. For a more detailed description of this requirement for the length scale, it is recommended to read Section 6 of Mellor \& Yamada (1982) and Nunes Vaz \& Simpson (1994).

It is worth noting that the replacement of $L$, arising from expression (24), in (17), provides an expression for the turbulent viscosity according to the ECT and the turbulent dissipation rate, as follows.

$$
\begin{aligned}
& K_{M}=c \sqrt{k} \cdot\left(c_{L} \frac{k^{3 / 2}}{\varepsilon}\right) \\
& K_{M}=\left(\mathrm{c} \cdot c_{L}\right) \cdot \frac{k^{2}}{\varepsilon}
\end{aligned}
$$

or

$$
K_{M}=c_{\mu} \cdot \frac{k^{2}}{\varepsilon}
$$

In expression (27), $c_{\mu}$ is an empirical constant with a value of 0.09 (Rodi, 1993; Burchard, 2002).

The turbulence models are developed to simulate turbulent mixing processes present in virtually all environmental flows. However, these processes only become important in certain regions of the flow which are subject to strong velocity gradients, as happens near solid surfaces or free surfaces. In oceanic flows, this region represents a relatively thin layer, called the boundary layer, located near the bottom (bottom boundary layer) and near the surface (surface boundary layer), where the velocity gradients are intense and the mixing processes are more effective. This layer will be discussed in the next subsection. Outside these regions, where the average velocity gradients are weak, the flow behaves in an almost laminar fashion and the turbulent model loses its effectiveness.

\section{Boundary layer approach}

The difference between the vertical and horizontal scales of motion within the boundary layer is so large that it allows substantial simplification in the equations of motion. All these simplifications receive the designation Boundary Layer Approach and consist of disregarding: (i) all the horizontal velocity gradients; and (ii) the vertical gradient of the vertical velocity, as a consequence of the incompressibility condition (continuity equation).

The application of this approach in the terms on the righthand side of Equation (25), or more specifically, in their production terms due to the shear and diffusion, described by Equations (19) and (23), transforms these terms into:

$$
\begin{aligned}
P_{k} & =K_{M}\left[\left(\frac{\partial U}{\partial z}\right)^{2}+\left(\frac{\partial V}{\partial z}\right)^{2}\right] \\
D & =\frac{\partial}{\partial z}\left[\left(K_{k}+\Gamma\right) \frac{\partial k}{\partial z}\right]
\end{aligned}
$$

The inclusion of these terms on the right hand side of the equality of Equation (25) simplifies it to the following form

$$
\begin{gathered}
\frac{\partial k}{\partial t}+U_{j} \frac{\partial k}{\partial x_{j}} \underbrace{K_{M}\left[\left(\frac{\partial U}{\partial z}\right)^{2}+\left(\frac{\partial V}{\partial z}\right)^{2}\right]}_{P_{k}} \\
+\underbrace{K_{H} \frac{g}{\rho_{o}} \frac{\partial \rho}{\partial z}}_{P_{B}}+\underbrace{\frac{\partial}{\partial z}\left[\left(\Gamma+K_{k}\right) \frac{\partial k}{\partial z}\right]}_{D}-\underbrace{c_{L} \frac{k^{3 / 2}}{L}}_{\varepsilon}
\end{gathered}
$$

It should be noted that the production terms due to the buoyancy and dissipation remain unchanged. This equation will be 
referred to hereafter as the $k$-equation. Equation (30) often appears written in its contracted form,

$$
\frac{\partial k}{\partial t}+U_{j} \frac{\partial k}{\partial x_{j}}=D+P_{k}+P_{B}-\varepsilon
$$

Summary of the equations: The following is a summary table of the equations which describe the average flow and the turbulence model with one equation (transport of $k$ ).

\begin{tabular}{|l|c|}
\hline \multicolumn{1}{|c|}{ Equations } & Unknowns \\
\hline$\frac{\partial U_{i}}{\partial x_{i}}=0$ & $U, V, W, P$ \\
$\frac{\partial U_{i}}{\partial t}+U_{j} \frac{\partial U_{i}}{\partial x_{j}}-f U_{j} \varepsilon_{i j 3}=-\frac{1}{\rho_{o}} \frac{\partial P}{\partial x_{i}}-\frac{\rho \mathrm{g}}{\rho_{o}} \delta_{i 3}+\frac{\partial}{\partial x_{j}}\left(\nu \frac{\partial U_{i}}{\partial x_{j}}-\overline{u_{i} u_{j}}\right)$ & $-\overline{u_{i} u_{j}}$ \\
\hline$\frac{\partial \Theta}{\partial t}+U_{i} \frac{\partial \Theta}{\partial x_{i}}=\frac{\partial}{\partial x_{i}}\left(\Gamma_{\theta} \frac{\partial \Theta}{\partial x_{i}}-\overline{u_{i} \theta}\right)$ & $\Theta,-\overline{u_{i} \theta}$ \\
\hline$\frac{\partial S}{\partial t}+U_{i} \frac{\partial S}{\partial x_{i}}=\frac{\partial}{\partial x_{i}}\left(\Gamma_{s} \frac{\partial S}{\partial x_{i}}-\overline{u_{i} s}\right)$ & $-\overline{u_{i} s}$ \\
\hline$-\overline{u_{i} u_{j}}=K_{M}\left(\frac{\partial U_{i}}{\partial x_{j}}+\frac{\partial U_{j}}{\partial x_{i}}\right)$ & $K_{M}$ \\
\hline$\overline{u_{i} \theta}=K_{H} \frac{\partial \Theta}{\partial x_{i}}$ and $-\overline{u_{i} s}=K_{H} \frac{\partial S}{\partial x_{i}}$ & $K_{H}=K_{M} / \sigma$ \\
\hline$\frac{\partial k}{\partial t}+U_{j} \frac{\partial k}{\partial x_{j}}=P_{k}+P_{B}+D-\varepsilon$ & $k$ \\
\hline$L[$ ramp model of Fig. 2 or Equation $(26)]$ & \\
\hline$K_{M}=c_{\mu} \frac{k^{2}}{\varepsilon}$ and $\varepsilon=c_{L} \frac{k^{3 / 2}}{L}$ & \\
\hline
\end{tabular}

The practice of prescribing a length scale which characterizes the turbulence is difficult to apply, except for flows with simple geometry. Therefore, it is ideal to determine the value of the characteristic length scale $L$, also from a transport equation, as has been done for the quantity $k$. These models are presented below.

\section{Models with two equations}

The introduction of a differential equation for the transport of a turbulent entity $(k)$ has inspired many researchers and, because of this, several models have emerged for the transport of other characteristic quantities of turbulence, many of which have been quite successful, due to the high level of generality and quality of the results (e.g., Eiger, 1989).

The manner in which the vortices of various sizes are distributed (in space and time) through the area of the flow, suggests using a transport equation, similar to the $k$-equation, for the length scale (dimensions) of the vortices. In a "turbulence grid" (Souza et al., 2011), for example, from the instant they are generated, the vortices are subject to various processes such as advection, diffusion, and dissipation, in a way that their sizes, at any location, depend not only on their initial dimensions but also the relative importance of each of these processes. As a result of this, it is observed that the length scale behaves as an entity representative of the turbulence, whose distribution can be predicted with the aid of a transport equation, just like any other turbulent quantities.

The equation for the transport of the length scale does not necessarily need to have the actual length scale $L$ as a dependent variable. Also, most of the equations proposed to date do not use it in such a way. Any combination of the type $\mathcal{Z}=k^{m} L^{n}$ will be sufficient, since the turbulent kinetic energy is already known from the solution to the $k$-equation (Rodi, 1993). The most im- 
Table 1 - Most important combinations and their authors.

\begin{tabular}{|c|c|c|c|c|c|}
\hline Quantity & Symbol & $m$ & $n$ & $\mathcal{Z}$ & Authors \\
\hline Dissipation rate & $\varepsilon$ & $03 / 2$ & -1 & $k^{3 / 2} / L$ & Jones \& Launder (1972) \\
\hline Product $k L$ & $k L$ & 1 & 1 & $k L$ & $\begin{array}{c}\text { Rodi \& Spalding (1970); } \\
\text { Mellor \& Yamada (1982) }\end{array}$ \\
\hline Frequency & $\omega$ & $01 / 2$ & -1 & $k^{1 / 2} / L$ & $\begin{array}{c}\text { Kolmogorov (1942); } \\
\text { Wilcox (1988) }\end{array}$ \\
\hline Vorticity & $\xi$ & 1 & -2 & $k / L^{2}$ & Wilcox (1988) \\
\hline
\end{tabular}

portant $k^{m} L^{n}$ combinations that have emerged over time, as well as their authors, are cited by Rodi (1993) and Deschamps (2002) and are reproduced in Table 1.

In general, the turbulence models with two equations use a transport equation for $k$ and another equation for an auxiliary variable. The most commonly employed models are: $k-\varepsilon, k-k L$ and $k-\omega$, with $\varepsilon, k L$ and $\omega$ being the auxiliary variables.

Launder \& Spalding (1972), apud Eiger (1989) showed that these three models are conceptually equivalent to each other because, knowing the results of one of them, the other variables can be readily obtained. Also, according to Eiger (1989), this does not mean an equivalence of results between the different models, since they are constructed differently. Below, the three models are presented in a unified way in the form of a $k-\mathcal{Z}$ model, in which $\mathcal{Z}$ can represent any of the auxiliary variables.

\section{The $k-\mathcal{Z}$ model}

The model thus conceived is comprised of two equations: Equation (31), which represents the transport of the turbulent kinetic energy $k$, rewritten below,

$$
\frac{\partial k}{\partial t}+U_{j} \frac{\partial k}{\partial x_{j}}=D+P_{k}+P_{B}-\varepsilon
$$

and a second equation for the transport of the length scale $L$, represented by the auxiliary variable $\mathcal{Z}$, which is written in order to display the same structural form of the first, assuming the following:

$$
\begin{gathered}
\frac{\partial \mathcal{Z}}{\partial t}+U_{j} \frac{\partial \mathcal{Z}}{\partial x_{j}}=\frac{\partial}{\partial z}\left[\left(\Gamma+K_{\mathcal{Z}}\right) \frac{\partial \mathcal{Z}}{\partial z}\right] \\
+\frac{\mathcal{Z}}{k}\left(c_{1} P_{k}+c_{3} P_{B}-c_{2} \varepsilon F_{\text {Wall }}\right)
\end{gathered}
$$

In this equation, the terms on the left hand side represent the local variation and the advective transport of the variable $\mathcal{Z}$, while on the right hand side the first part represents the diffusive transport. In the second term on the right hand side, production terms (due to the shear $P_{k}$ and the buoyancy $P_{B}$ ) and the dissipation $\varepsilon$, (which is already defined) appear, accompanied by the coefficients $c_{1}, c_{3}$ and $c_{2}$, respectively, which must be determined experimentally for each model. The values assumed for these coefficients in each model are presented in Table 2.

Table 2 - Parameters used in each model.

\begin{tabular}{|c|c|c|c|c|c|c|}
\hline Model & $c_{1}$ & $c_{2}$ & $c_{3}$ & $\sigma_{k}$ & $\sigma_{Z}$ & $F_{\text {wall }}$ \\
\hline$k-\varepsilon$ & 1.44 & 1.92 & 1.0 & 1.0 & 1.3 & 1.0 \\
$k-k L$ & 0.9 & 0.5 & 0.9 & 2.44 & 2.44 & Eq. (35) \\
$k-\omega$ & 0.555 & 0.833 & 1.0 & 2.0 & 2.0 & 1.0 \\
\hline
\end{tabular}

In Equation (33), $K_{\mathcal{Z}}=K_{M} / \sigma_{\mathcal{Z}}$ is the turbulent diffusivity of the variable $\mathcal{Z}$, and $\sigma_{\mathcal{Z}}$ is the turbulent Schmidt number, whose values adopted in each model are also cited in Table 2. The relationships between the different turbulent variables allow us to obtain the length macro-scale of the respective models, given by:

$$
L=\frac{(k L)}{k} \quad L=c_{z} \frac{k^{3 / 2}}{\varepsilon} \quad L=c_{z} \frac{k^{1 / 2}}{\omega}
$$

in which $c_{z}=\left(c_{\mu}^{0}\right)^{3 / 4}$, and $c_{\mu}^{0}=0.094$ (see Burchard, 2002).

In the $k-k L$ model, it is necessary to use an approximation function from the wall, $F_{W a l l}$. This model uses a transport equation precisely for the characteristic length scale from the large scales of the turbulence or from the large vortices (more energetic), which are related to the average flow which, in turn, is the energy source that feeds the turbulence. Near a solid surface, however, this scale is drastically reduced, by physical limitations, and moves towards zero, as Figure 2 suggests. Therefore, it is necessary to inform the model about the existence of boundaries near the point analyzed. This is done with the wall function approach, $F_{W a l l}$, which aims to ensure the reduction of the length scale calculated near these boundaries. 
In this regard, Mellor \& Yamada (1982) have already recognized that this function was absolutely necessary to guarantee positive viscosity and diffusivity coefficients. Warner et al. (2005) proved that all of the models with a positive $n$ exponent in the expression $\mathcal{Z}=k^{m} L^{n}$ require the wall function approach to ensure the positivity of these coefficients (see Table 1). According to Umlauf \& Burchard (2003) and Warner et al. (2005), in the $k-\varepsilon$ and $k-\omega$ models the modeled entity $(\varepsilon$ or $\omega$ ) is already characteristic of the small scales of turbulence, thus eliminating the need to inform the proximity of boundaries.

According to Burchard (2002), since the 1970s a controversial discussion has raged about which of the two scales ( $k L$ or $\varepsilon)$ has greater physical relevance; that is, which one is "more solid" in terms of physical concepts that govern turbulence in all its scales. To give you an idea of this discussion, Burchard (2002) draws our attention to the arguments of two important characters in turbulence modeling. Here we will try to reproduce these arguments:

Mellor \& Yamada (1982, page 861)

While we cannot claim great confidence in the equation, we prefer it to the differential equation for the dissipation rate $\varepsilon$.

...fundamentally, it seems wrong for us to use an equation which describes the small scales of turbulence $(\varepsilon)$ in order to determine the turbulent macro-scale required. Operationally, however, after a few terms being modeled, the transport equation of the dissipation $(\varepsilon)$ is a particular case of a more general transport equation of the length scale $(k L)$.

Rodi (1987, page 5311)

The arguments about the relative merits of the equations $\varepsilon$ and $k L$ are somewhat academic because both equations are completely empirical and, with the constants conveniently adjusted, they show similar performance. The difference is that the $k L$ equation requires an additional "wall approach" term, whereas the $\varepsilon$ equation does not.

It is clear from the citations above that both models have good physical rationale; that is, this should not be the criterion for the preferential choice of one over the other. Another important thing from these citations is that there is a need to adopt a wall function approach for the $k$ - $k L$ model. Blumberg \& Mellor
(1987) use a wall function approach with the following form,

$$
F_{W a l l}\left(1+E\left(\frac{L}{\kappa L_{Z}}\right)^{2}\right)
$$

in which $L_{Z}$ is a length scale defined by $L_{Z}^{-1}=d_{S}^{-1}+d_{F}^{-1}$, $E=1,33$ is a constant, $d_{S}$ and $d_{F}$ represent the distances to the surface and to the bottom, respectively, and $\kappa=0.41$ is the von Karman constant.

The following table is a summary of the equations describing the average flow and the two-equation turbulence model.

We must keep in mind that when we choose an equation for " $\varepsilon$ ", " $\omega$ " or for " $k L$ ", we are actually looking to discover the length macro-scale of the turbulence in order to - with the aid of Equation (17) - determine the viscosity and diffusivity coefficients.

In this section we have the opportunity to mention a variety of classical turbulence models. Of the two-equation models we quoted and analyzed in most detail, the $k-\varepsilon$ and $k-k L$ models are the most widely used models in oceanic and atmospheric modeling, according to Burchard (2002). The $k-\omega$ model, in which $\omega$ is the characteristic frequency of the vortices, was also mentioned and it has only recently gained some popularity in ocean modeling with the adaptations provided by Umlauf et al. (2003).

\section{DISCUSSION AND FINAL CONSIDERATIONS}

An important concept about turbulence was highlighted in this study: it is an entity that can be generated, transported by advection or diffusion, and dissipated. A model that intends to be reasonably realistic and general must be capable of considering these processes. However, many models, even very successful ones in some cases, do not meet these requirements and therefore should not be extrapolated for conditions that are very different to those for which they have been validated (e.g., Eiger, 1989), as is the case with the equationless transport models.

The fact that turbulence is capable of transport led to the proposal of a classification criterion for the turbulence models, according to the number of partial differential transport equations considered. Some models are based on algebraic equations which relate the turbulent quantities to the average flow variables and, therefore, do not consider the transport of turbulence.

The turbulence models, either with constant turbulent viscosity or variable viscosity, present some shortcomings, including the fact of not considering the transport of turbulence; that is, the coefficients of turbulent viscosity and diffusivity are assumed to be constant or a function of local quantities only, defined for 


\begin{tabular}{|c|c|}
\hline Equations of the $k$ - $\mathcal{Z}$ model & Unknowns \\
\hline$\frac{\partial U_{i}}{\partial x_{i}}=0$ & $U, V, W, P$ \\
\hline$\frac{\partial U_{i}}{\partial t}+U_{j} \frac{\partial U_{i}}{\partial x_{j}}-f U_{j} \varepsilon_{i j 3}=-\frac{1}{\rho_{o}} \frac{\partial P}{\partial x_{i}}-\frac{\rho \mathrm{g}}{\rho_{o}} \delta_{i 3}+\frac{\partial}{\partial x_{j}}\left(\nu \frac{\partial U_{i}}{\partial x_{j}}-\overline{u_{i} u_{j}}\right)$ & $-\overline{u_{i} u_{j}}$ \\
\hline$\frac{\partial \Theta}{\partial t}+U_{i} \frac{\partial \Theta}{\partial x_{i}}=\frac{\partial}{\partial x_{i}}\left(\Gamma_{\theta} \frac{\partial \Theta}{\partial x_{i}}-\overline{u_{i} \theta}\right)$ & $\Theta,-\overline{u_{i} \theta}$ \\
\hline$\frac{\partial S}{\partial t}+U_{i} \frac{\partial S}{\partial x_{i}}=\frac{\partial}{\partial x_{i}}\left(\Gamma_{s} \frac{\partial S}{\partial x_{i}}-\overline{u_{i} s}\right)$ & $S,-\overline{u_{i} S}$ \\
\hline$\frac{\partial k}{\partial t}+U_{j} \frac{\partial k}{\partial x_{j}}=K_{M}\left[\left(\frac{\partial U}{\partial z}\right)^{2}+\left(\frac{\partial V}{\partial z}\right)^{2}\right]+K_{H} \frac{g}{\rho_{o}} \frac{\partial \rho}{\partial z}+\frac{\partial}{\partial x_{j}}\left[\left(\Gamma_{S}+K_{k}\right) \frac{\partial k}{\partial x_{j}}\right]-c_{L} \frac{k^{3 / 2}}{L}$ & $k$ \\
\hline$\frac{\partial \mathcal{Z}}{\partial t}+U_{j} \frac{\partial \mathcal{Z}}{\partial x_{j}}=\frac{\partial}{\partial z}\left[\left(\Gamma+K_{\mathcal{Z}}\right) \frac{\partial \mathcal{Z}}{\partial z}\right]+\frac{\mathcal{Z}}{k}\left(c_{1} P_{S}+c_{3} P_{B}-c_{2} \varepsilon F_{\text {wall }}\right)$ & $\begin{array}{c}\mathcal{Z}=\varepsilon \\
\mathcal{Z}=k L \\
\mathcal{Z}=\omega\end{array}$ \\
\hline$K_{M}=c_{\mu} \frac{k^{2}}{\varepsilon}, \quad K_{H}=\frac{K_{M}}{\sigma}, \quad K_{k}=\frac{K_{M}}{\sigma_{k}} \quad$ and $\quad K_{\mathcal{Z}}=\frac{K_{M}}{\sigma_{\mathcal{Z}}}$ & \\
\hline$-\overline{u_{i} u_{j}}=K_{M}\left(\frac{\partial U_{i}}{\partial x_{j}}+\frac{\partial U_{j}}{\partial x_{i}}\right)$ & \\
\hline$-\overline{u_{i} \theta}=K_{H} \frac{\partial \Theta}{\partial x_{i}} \quad-\overline{u_{i} s}=K_{H} \frac{\partial S}{\partial x_{i}}$ & \\
\hline
\end{tabular}

the average flow. This means that, for these models, the turbulence at a point is independent of the turbulence at other locations of the flow; that is, the turbulence at a location neither influences nor is influenced by the turbulence elsewhere in the flow. For these models, a condition of local equilibrium predominates, in which the mechanisms of advection and diffusion of turbulence are neglected, and the turbulence is dissipated at the same location where it is generated (e.g., Buchard, 2002).

The turbulence models with variable viscosity transfer the problem of determining the viscosity to the problem of determining the mixing length, which must be prescribed. In flows with simple geometry this is not really a serious problem; however, in flows with complex geometry it can be very difficult to correctly determine the mixing length. For geophysical flows, this length scale can be prescribed with the aid of Figure 2, for example.
In the models with a transport equation, generally an equation for the turbulent kinetic energy, the shortcomings cited do not occur because the mechanisms of advection and diffusion are included in this equation, which provides $k$ for use in Equation (17). The turbulence at one point then starts to influence and be influenced by the turbulence at other points of the flow, which represents a major advance over previous models. According to Deschamps (2002), the major shortcoming of the one-equation models, and also of the formulation of the mixing length, is the need to prescribe a length scale, characteristic of the turbulence, in order to sustain Equation (17) and allow the turbulent viscosity to be determined. We should not, however, conclude that little progress has been made with the introduction of the turbulent kinetic energy equation into the model. It ensured that several innovative concepts in relation to the zero-equation models were 
introduced; for example: (i) considering $k$ as a measure of the turbulence intensity, a concept that has more solid foundations than the measures for the mixing length; and (ii) the presence of a transport equation for $k$ stressed that the turbulence at one point affects and is affected by the turbulence at other points of the flow (e.g., Eiger, 1989).

With the development of the two-equation transport models, one for the turbulent kinetic energy and the other for the characteristic length scale of the turbulence, the prescription problem of this latter scale for Equation (17) was overcome. The fact that these two scales are determined by differential transport equations gives such models greater generality.

We must keep in mind that when we choose an equation for $\varepsilon, \omega$ or for $k L$ - variables that in Equation (33) are represented by the auxiliary variable $\mathcal{Z}$ - we are actually looking to know the length macro-scale of the turbulence so that, with the aid of Equation (17), we may determine the viscosity and diffusivity coefficients. Among the algebraic turbulence models; that is, those that use an algebraic equation like Equation (17) to determine the turbulent viscosity, the models with two equations are considered to be the most complete.

The choice of model for the simulation of turbulent flow must satisfy certain desirable assumptions. In principle, the model must be mathematically simple and involve the least possible number of physical concepts. It should also be capable of simulating the largest possible number of flows without needing to adjust its constants or constituent equations. Finally, the model must be numerically stable (e.g., Deschamps, 2002). However, the complexity of the geophysical flows does not enable indication that a particular turbulence model is more (or less) suitable for a certain hydrodynamic situation of interest. The choice of a simpler turbulence model may ultimately inhibit certain phenomena involved in the process under study, which would only be known to the researcher when he compares his results (if possible) with those derived from the use of more complex models. The use of simpler models is attractive to the user, since these models require less computational effort, thus allowing results to be obtained more quickly.

An example of how the choice of turbulence model affects the final outcome of a certain process being studied can be found in Xing \& Davies (1999). These authors studied the influence of the intensity and direction of the wind on the scattering of an estuarine plume. In this study, the effect of tidal currents was not considered; however, three turbulent closure models were coupled to the hydrodynamic model: a two-equation model (Mellor \& Yamada, 1982, or MY82) and two one-equation models, which solve the equation for turbulent kinetic energy but prescribe the length scale differently. According to the authors, in the simulations with no wind, the results were similar; however, significant differences were observed between the models when the wind action was considered.

In a second example, Blaise et al. (2007) used RANS models in the investigation of tidal flow around Rattray Island in the Great Barrier Reef, in Australia, which causes the appearance of vortices in the wake of the motion. They claim that the elevated turbidity of the surface water suggests intense upwelling that is capable of transporting sediments from the bottom to the surface. Based on previous numerical studies it was unclear whether the most intense upwelling occurs near the center of the vortices, relatively far from the island, or near the headlands of the island. According to Blaise et al. (2007), all of these past studies used simple turbulent closure models of the zero-equation type, whereby the vertical viscosity coefficient is calculated via an algebraic expression. In this study, the authors evaluated the influence of the turbulent closure on the results of the numerical model. They modeled the flow around the island using a simple algebraic model and the two-equation model (from Mellor \& Yamada, 1982). Also according to the authors, the upwelling velocity was significantly influenced by the two-equation model in terms of the algebraic closure. The difference was explained by the turbulent viscosity which, on average, was lower with the twoequation model, leading to a smaller mixture and a greater vertical shearing in the horizontal velocity near the bottom, which explains the increase in the upwelling at the center of the vortices.

Even after choosing a particular turbulent closure scheme, like the one with two equations, the choice of the variable $(\omega, \varepsilon, L)$ representative of the length scale of the turbulence $\mathcal{Z}$ may affect the results obtained in the numerical simulation of the process under study. This can be seen in the experiment for deepening of the oceanic mixture layer through the action of a constant and uniform wind acting on the sea surface, which was presented in Souza et al. (2013) and included the comparison of three two-equation turbulence models coupled to the same hydrodynamic model. The results showed that, although the models are the same type, the simulations produce small differences, which the authors attributed to the different relative importance that each model gives to different physical processes involved in the turbulent closure scheme; for example, shear, buoyancy, and dissipation. Figure 3 shows the temporal evolution of the deepening of the oceanic mixture layer from numerical simulations that differ among themselves due to the turbulent closure scheme used. 


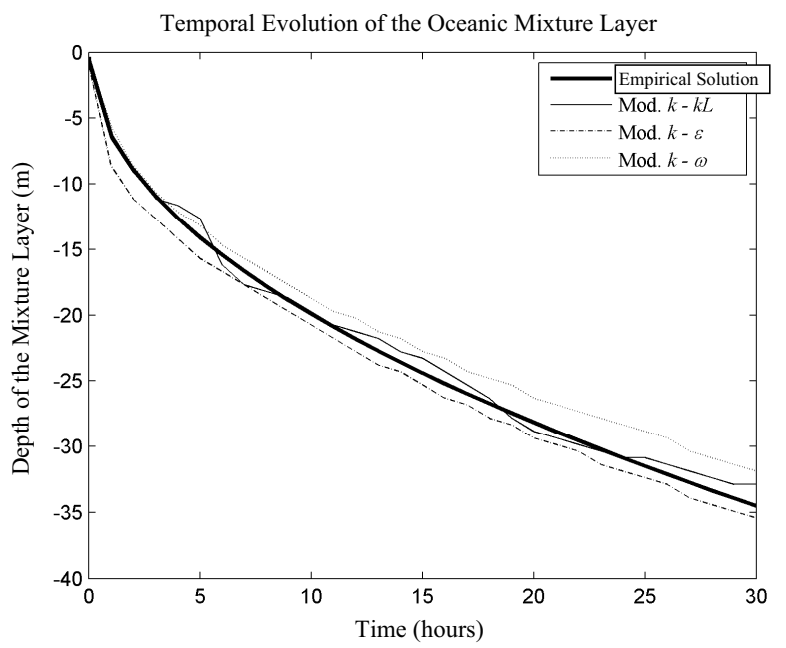

Figure 3 - Temporal evolution of the deepening of the oceanic mixture layer from numerical simulations that differ among themselves due to the turbulent closure scheme used. The empirical solution was obtained experimentally (more details in Souza et al., 2013).

\section{REFERENCES}

BAUMERT H \& PETERS H. 2000. Second-Moment Closures and Length Scales for Weakly Stratified Turbulent Shear Flows. Journal of Geophysical Research, 105(C3): 1067-1084.

BLAISE S, DELEERSNIJDER E, WHITE L \& REMACLE JF. 2007. Influence of the turbulence closure scheme on the finite-element simulation of the upwelling in the wake of a shallow-water island. Continental Shelf Research, 27: 2329-2345.

BLUMBERG AF \& MELLOR GL. 1987. A Description of a Three-Dimensional Coastal Ocean Circulation Model. In: HEAPS NS (Ed.). Three dimensional ocean models. American Geophysical Union, Washington D.C. p. $1-16$.

BURCHARD H. 2002. Applied Turbulence Modelling in Marine Waters. Lecture Notes in Earth Sciences. Springer-Verlag, Germany. 215 pp.

BURCHARD H \& BOLDING K. 2001. Comparative Analysis of Four Second-Moment Turbulence Closure Models for the Oceanic Mixed Layer. Journal of Physical Oceanography, 31: 1943-1968.

CANUTO VM, HOWARD AM, CHENG Y, MULLER CJ, LEBOISSETIER A \& JAYNE SR. 2010. Ocean Turbulence, III: New GISS Vertical Mixing Scheme. Ocean Modelling, 34: 70-91.

CHAO SY. 1988. Wind-Driven Motion of Estuarine Plumes. Journal of Physical Oceanography, 18: 1144-1166.

CHAO SY \& BOICOURT WC. 1986. Onset of Estuarine Plumes. Journal of Physical Oceanography, 16: 2137-2149.

DESCHAMPS CJ. 2002. Modelos Algébricos e Diferenciais. In: Coleção Cadernos de Turbulência. Associação Brasileira de Ciências Mecânicas - ABCM. Rio de Janeiro. Vol. 1, Cap. 3, p. 101-155.
DURSKI SM, GLENN SM \& HAIDVOGEL DB. 2004. Vertical mixing schemes in the coastal ocean: comparison of the level 2.5 MellorYamada scheme with an enhanced version of the $K$-profile parameterization. Journal of Geophysical Research, 109, C01015, doi: 10.1029/ 2002JC001702.

EIGER S. 1989. Modelos de Escoamentos Turbulentos. In: SILVA RCV (Ed.). Métodos Numéricos em Recursos Hídricos. Coleção da ABRH Associação Brasileira de Recursos Hídricos. Vol. 1, Cap. 2, p. 84-155.

FONTOURA RODRIGUES JLA. 2003. Escoamentos Turbulentos Parietais. In: Coleção Cadernos de Turbulência. Associação Brasileira de Ciências Mecânicas - ABCM. Rio de Janeiro. Vol. 2, Cap. 3, p. 153-204.

GALPERIN B, ROSATI A, KANTHA LH \& MELLOR GL. 1989. Modeling Rotating Stratified Turbulent Flows with Application to Oceanic Mixed Layers. Journal of Physical Oceanography, 19: 901-916.

GARVINE RW. 1999. Penetration of Buoyant Coastal Discharge onto the Continental Shelf: A Numerical Model Experiment. Journal of Physical Oceanography, 29: 1892-1909.

HASSID S \& GALPERIN B. 1983. A Turbulent Energy Model for Geophysical Flows. Boundary-Layer Meteorology, 26: 397-412.

ILICAK M, ÖZGÖKMAN TM, PETERS H, BAUMERT H \& ISKANDARANI M. 2008. Performance of two-equation turbulence closures in threedimensional simulations of the Red Sea overflow. Ocean Modelling, 24: 122-139.

JONES WP \& LAUNDER BE. 1972. The prediction of laminarization with a two-equation model of turbulence. International Journal of Heat and Mass Transfer, 15: 301-314.

KANTHA LH \& CLAYSON CA. 1994. An Improved Mixed Layer Model for Geophysical Applications. Journal of Geophysical Research, 99(C12): 25235-25266.

KUNDU PK \& COHEN IM. 2002. Fluid Mechanics. Academic Press Inc., 2 ed., $730 \mathrm{pp}$.

LARGE WG, MCWILLIAMS JC \& DONEY SC. 1994. Ocean vertical mixing: a review and a model with a nonlocal boundary layer parameterization. Reviews of Geophysics, 32: 363-403.

LESIEUR M, MÉTAIS 0 \& COMTE P. 2005. Large-Eddy Simulations of Turbulence. Cambridge University Press. 232 pp.

LIU WC, HSU MH \& KUO AY. 2002. Application of Different Turbulence Modeling Methods for Quantifying Coastal Ocean Turbulence and Mixing. Mathematics and Computers in Simulation, 59: 437-451.

MARQUES WC, FERNANDES EH, MONTEIRO IO \& MÖLLER 00. 2009. Numerical Modeling of the Patos Lagoon Coastal Plume, Brazil. Continental Shelf Research, 29: 556-571.

MARTINEZ DMV. 2006. Transição à Turbulência na Camada de Mistura Estavelmente Estratificada utilizando Simulação Numérica Direta 
e Simulação de Grandes Escalas. Doctorade Thesis. Instituto de Pesquisas Hidráulicas, Universidade Federal do Rio Grande do Sul. 152 pp. Available on: http://www.lume.ufrgs.br/handle/10183/7230. Access on: Dec. 01, 2012

MELLOR GL \& YAMADA T. 1974. A Hierarchy of Turbulence Closure Models for Planetary Boundary Layers. Journal of Atmospheric Sciences, 31: 1791-1806.

MELLOR GL \& YAMADA T. 1982. Development of a Turbulence Closure Model for Geophysical Fluid Problems. Reviews of Geophysics and Space Physics, 20: 851-875.

MÜLLER TJ, IKEDA Y, ZANGENBERG N \& NONATO LV. 1998. Direct measurements of western boundary currents off Brazil between $20^{\circ} \mathrm{S}$ and $28^{\circ} \mathrm{S}$. Journal of Geophysical Research, 103(C3): 5429-5437, doi: 10.1029/97JC03529.

NUNES VAZ RA \& SIMPSON JH. 1994. Turbulence closure modeling in estuarine stratification. Journal of Geophysical Research, 99(C8): 16143-16160.

OLIVEIRA LR. 2003. Estudo da Variabilidade da Corrente do Brasil a $28^{\circ} \mathrm{S}$. Master Dissertation on Oceanografia Física, Química e Geológica. Instituto de Oceanografia. Universidade Federal do Rio Grande. 88 pp.

PALMA ED \& MATANO RP. 2012. A numerical study of the Magellan Plume. Journal of Geophysical Research, 117(C05041), doi: 10.1029/ 2011JC007750.

PIMENTA FM, KIRWAN Jr AD \& HUQ P. 2011. On the Transport of Buoyant Plumes. Journal of Physical Oceanography, 41: 620-640.

POPE SB. 2008. Turbulent Flows. Cambridge University Press. Fifth printing with corrections. $771 \mathrm{pp}$.

RODI W. 1993. Turbulence Models and their Application in Hydraulics - A state-of-the-art review. International Association for Hydraulic Research - IAHR, 3 ed., 104 pp.

RODI W \& SPALDING DB. 1970. A two-parameter model of turbulence and its application to free jets. Wärme-und Stoffübertragung, 3(2): 8595.

SCHWIND JJ. 1980. Geophysical Fluid Dynamics for Oceanographers. Prentice-Hall Inc., 307 pp.

SILVESTRINI JH. 2003. Simulação Numérica Direta e de Grandes Escalas de Escoamentos Transicionais e Turbulentos. In: Coleção Cadernos de Turbulência. Associação Brasileira de Ciências Mecânicas - ABCM. Rio de Janeiro. Vol. 2, Cap. 1, p. 1-81.
SMAGORINSKY J. 1963. General Circulation Experiments with the Primitive Equations. I. The Basic Experiment. Monthly Weather Review, 91(3): 99-164.

SOUZA JFA. 2011. Um Estudo dos Processos de Mistura em Correntes Costeiras sob Diferentes Concepções de Fechamento Turbulento. Doctorade Thesis on Oceanografia Física, Química e Geológica. Instituto de Oceanografia. Universidade Federal do Rio Grande. 196 pp.

SOUZA JFA, OLIVEIRA LR, AZEVEDO JLL, SOARES ID \& MATA MM 2011. Uma Revisão sobre a Turbulência e sua Modelagem. Revista Brasileira de Geofísica, 29(1): 21-41.

SOUZA JFA, AZEVEDO JLL, SOARES ID, OLIVEIRA LR \& MATA MM. 2013. Incorporação de dois novos esquemas de fechamento turbulento ao Princeton Ocean Model (POM). Revista Brasileira de Geofísica, 31(3): 17-30.

SOUZA JFA, AZEVEDO JLL, OLIVEIRA LR, SOARES ID \& MATA MM. A Modelagem da Turbulência em Escoamentos Geofísicos: Parte II - Modelos de Fechamento Turbulento de Segunda Ordem. Revista Brasileira de Geofísica (manuscript submitted for publication).

STULL RB. 1988. An Introduction to Boundary Layer Meteorology. Kluwer Academic Publishers. Reprinted with errata-1997. 667 pp.

UMLAUF L \& BURCHARD H. 2003. A generic length-scale equation for geophysical turbulence models. Journal of Marine Research, 61: 235-265.

UMLAUF L BURCHARD H \& HUTTER K. 2003. Extending the $k$ - $\omega$ turbulence model towards oceanic applications. Ocean Modelling, 5 : 195-218.

VERDIER-BONNET C, ANGOT P, FRAUNIE P \& COANTIC M. 1999. Three-dimensional Modelling of a Coastal Circulations with different closures. Journal of Marine Systems, 21: 321-339.

WARNER JC, SHERWOOD CR, ARANGO HG \& SIGNELL RP. 2005. Performance of a four turbulence closure models implemented using a generic length scale method. Ocean Modelling, 8: 81-113.

WILCOX DC. 1988. Reassessment of the scale-determining equation advanced turbulence models. AIAA Journal, 26(11): 1299-1310.

XING J \& DAVIES AM. 1999. The effect of wind direction and mixing upon the spreading of a buoyant plume in a non-tidal regime. Continental Shelf Research, 19: 1437-1483. 


\section{NOTES ABOUT THE AUTHORS}

José Francisco Almeida de Souza. Graduated in Civil Engineering from FURG (1979), Master's degree in Civil Engineering, specializing in Hydric Resources and Sanitation - UFRGS (1990), and Doctorate degree in Physical, Chemical, and Geological Oceanography - FURG (2011). Currently professor at the Escola de Engenharia (EE) of FURG and involved in research for turbulence modeling with application in fluctuating plume formation using the Princeton Ocean Model (POM). Area of interest: the turbulent aspects of the coastal and estuarine circulation.

José Luiz Lima de Azevedo. Graduated in Chemical Engineering from FURG (1982), Master's degree in Electrical Engineering - UFSC (1996), and Doctorate degree in Physical, Chemical, and Geological Oceanography - FURG (2009). Since 1984 professor at FURG and involved in research for analytical and numeric modeling of the encounter of anti-cyclonic vortices with the continental border and the respective boundary current. Area of interest: numeric modeling, using the Princeton Ocean Model (POM) and the Bleck \& Boudra model, and the study of climatological data originating from the profiling floats of the ARGO project.

Leopold o Rota de Oliveira. Graduated in Physics from UFPEL (1998). Master's (2003) and Doctorate (2008) degrees in Physical, Chemical, and Geological Oceanography at FURG. Physics professor for 4 years at UFPEL/FURG. Scientific works emphasize Physical Oceanography, and medium and large scale oceanic circulation. The main subjects and regions are: spatial and temporal variability, conversions of energies associated with dynamic instabilities, inverse energy cascade and superficial heat flux of oceanic currents for the Southwest Atlantic and Austral Ocean.

Ivan Dias Soares. Graduated in Oceanology from FURG (1986). Master's degree in Physical Oceanography at USP (1995) and Doctorate degree in Meteorology and Physical Oceanography at Rosenstiel School of Marine and Atmospheric Science, University of Miami, Florida, USA (2003).

Maurício Magalhães Mata. Graduated in Oceanography from FURG (1991) and Master's degree in Remote Sensing at UFRGS (1996). Doctorate degree in 2001 in Physical Oceanography from Flinders University of South Australia, Adelaide, Australia. Permanent professor at the Oceanographic Institute of FURG since 1992. Research area is medium and large scale oceanic circulation, emphasizing west boundary currents and Antarctic Oceanography. Special interest in the inter-annual processes that control the formation and exportation of bottom waters around the Antarctic continent. 